Research Paper

\title{
Endothelial Progenitor Cells Predict Long-Term Mor- tality in Hemodialysis Patients
}

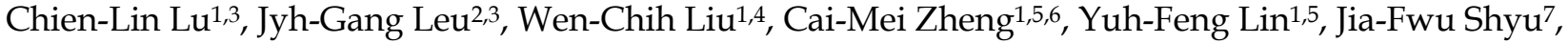 \\ Chia-Chao $\mathrm{Wu}^{8, *}$, Kuo-Cheng $\mathrm{Lu}^{9, *}, \mathbb{}$
}

1. Graduate Institute of Clinical Medicine, College of Medicine, Taipei Medical University, Taipei, Taiwan

2. School of Medicine, College of Medicine, Fu-Jen Catholic University, New Taipei, Taiwan

3. Division of Nephrology, Department of Medicine, Shin-Kong Wu Ho-Su Memorial Hospital, Taipei, Taiwan.

4. Division of Nephrology, Department of Internal Medicine, Yonghe Cardinal Tien Hospital, New Taipei City, Taiwan

5. Division of Nephrology, Department of Internal Medicine, Shuang Ho Hospital, Taipei Medical University, Taiwan

6. Division of Nephrology, Department of Internal Medicine, School of Medicine, College of Medicine, Taipei Medical University

7. Department of Biology and Anatomy, National Defense Medical Center, Taipei, Taiwan

8. Division of Nephrology, Department of Medicine, Tri-Service General Hospital, National Defense Medical Center, Taipei, Taiwan.

9. Department of Medicine, Cardinal Tien Hospital, School of Medicine, Fu Jen Catholic University, New Taipei City, Taiwan.

* These authors have contributed equally to this work.

$\triangle$ Corresponding author: Dr. Kuo-Cheng Lu, Division of Nephrology, Department of Medicine, Cardinal Tien Hospital, School of Medicine, Fu-Jen Catholic University, 362, Chung-Cheng Rd, Hsin-Tien, New Taipei City, Taiwan. Tel.: +886 2 29155739; Fax: +886 2 29107920. E-mail: kuochenglu@gmail.com

(C) Ivyspring International Publisher. Reproduction is permitted for personal, noncommercial use, provided that the article is in whole, unmodified, and properly cited. See http://ivyspring.com/terms for terms and conditions.

Received: 2015.10.24; Accepted: 2016.01.22; Published: 2016.02.20

\begin{abstract}
Background: The endothelial progenitor cells (EPCs) dysfunction is a critical event in the initiation of atherosclerotic plaque development and the level of circulating EPCs can be considered a biomarker of cardiovascular events. The level and functional change in EPCs has been investigated in hemodialysis patients, but the effect of absolute number of EPCs on risk of death has not yet been explored. We hypothesized that the number of EPCs predicted death from cardiovascular and all-cause mortality in hemodialysis patients.

Methods: We evaluate the association between endothelial progenitor cells and clinical outcome in 154 patients on maintenance hemodialysis. The blood sample was drawn at the time of patient enrollment and EPCs were identified by flow cytometry using triple staining for CD34/CD133/KDR.

Results: The median duration of follow-up was 4.19 years. There were $79(51.3 \%)$ deaths during the follow-up period, 41 of whom died due to a confirmed cardiovascular cause. The cumulative survival was greater in the high-EPC group than the low-EPC group for all-cause and cardiovascular mortality. Decreased EPCs levels were associated with a significant increase in the risk of cardiovascular and all-cause mortality after adjusting for age, gender, current smokers, diabetes mellitus, and hypertension.

Conclusions: The level of circulating EPCs independently predicts the clinical outcome in patients on maintenance hemodialysis. Thus, the EPCs levels may be a useful predictive tool for evaluating the risk of death in maintenance hemodialysis patients.
\end{abstract}

Key words: endothelial progenitor cells, hemodialysis, mortality

\section{Introduction}

Circulating endothelial progenitor cells (EPCs) are bone-marrow derived CD34+ mononuclear cells (MNCs) capable of new vessel formation in ischemic injury, a process termed postnatal vasculogenesis. The EPCs induce proliferation, migration, and adhesion and further differentiate into fully functional endothelial cells to maintain vascular integrity. EPCs migrate from the bone marrow to the systemic circulation and damaged tissue, and then incorporate into the vascular endothelial cell monolayer after differen- 
tiating into mature endothelial cells. Numerous factors have been reported to be involved in EPC migration, including stromal-derived factor 1 (SDF1), vascular endothelial growth factor (VEGF), interleukin 8, and nitric oxide (1).

Cardiovascular disease is the leading cause of death in chronic kidney disease (CKD), particularly entry to hemodialysis. CKD shares many risk factors with cardiovascular disease, and one disease may lead to the other. Hypertension, diabetes mellitus, and hyperlipidemia are the major risk factors in the development of endothelial dysfunction and atherosclerotic plaque formation. Even minor renal functional impairment can trigger endothelial dysfunction or promote chronic inflammation, resulting in atherosclerosis and causing further cardiovascular morbidity and mortality (2). Elevated levels of circulating endothelial cells and a deficit of two angiogenic factors, VEGF and angiopoietin-1, indicate the destruction of vascular hemostasis and defective vascular repair as renal function deteriorates (3). Although the level and functional change in EPCs has been investigated in hemodialysis patients, the relationship between the absolute number of $\mathrm{CD}_{4} 4^{+} / \mathrm{CD} 133^{+} / \mathrm{KDR}^{+}$ (Kinase insert domain-conjugating receptor) EPCs and risk of death has not yet been explored.

Here, we proposed that circulating EPCs are associated with the risk of death and clarify the predictive values of circulating EPCs in long term mortality in hemodialysis patients.

\section{Subjects and Methods}

\section{Patients}

From May 2009 to September 2014, 154 patients undergoing maintenance hemodialysis for $>3$ months at Cardinal Tien Hospital (New Taipei City, Taiwan) were enrolled in our study (72 men, 82 women). The median duration of follow-up was 4.19 years (mean $3.78 \pm 1.41$ years, range $0.15-5.08$ years). The duration of hemodialysis was $8.66 \pm 4.3$ years (range $4-24$ years). We excluded subjects who switched to peritoneal dialysis, performed renal transplantation and presented with fever or other sign of acute infection and chronic inflammation. Causes of death related to cardiovascular complications included sudden death, heart failure, myocardial infarction, cerebral infarction, and cerebral hemorrhage. All patients provided written informed consent for participation and the study was performed in accordance with the Declaration of Helsinki. Data on survival status and causes of death were retrieved by a review of hospital records and rechecked by the Taiwan Society of Nephrology: Kidney Dialysis, Transplantation (TSN KiDiT) registration system. This study was approved by the $\mathrm{Hu}-$ man Ethical Committees of Cardinal Tien Hospital.

\section{Clinical and laboratory parameters}

The clinical characteristics of the patients, including age, gender, and duration of hemodialysis, were obtained from medical records. Each patient was interviewed face to face at the time of enrollment regarding cigarette smoking status and alcohol consumption. Individuals who had not smoked more than 100 cigarettes in their lifetime were classified as never-smokers based on common conventions in epidemiological research. The pattern of drinking, including frequency of drinking days and number of drinks consumed in a day, was recorded. Patients who drank a bottle of alcoholic beverage (including beer, rice beer, and sorghum liquor) or more per month for at least 1 year were defined as ever drinkers. Current and former smokers were grouped together in the smoker's group and compared to individuals in the never-smoker's group. The ever drinker's group was compared to individuals in the non-drinkers group. Body weight was used to calculate the body mass index (BMI). Systolic blood pressure and diastolic blood pressure were measured in the supine position after a 10-15 minute rest. The definition of hypertension was based on the Seventh Joint National Committee: systolic blood pressure before dialysis $\geq 140 / 90 \mathrm{mmHg}$ or antihypertensive treatment. All of the participants met the diagnostic criteria for diabetes mellitus set forth by the American Diabetes Association: fasting glucose $\geq 126 \mathrm{mg} / \mathrm{dL}$ (7.0 mmol/L) or 2-h plasma glucose $\geq 200 \mathrm{mg} / \mathrm{dL}$ $(11.1 \mathrm{mmol} / \mathrm{L})$ after $75 \mathrm{~g}$ oral glucose loading test, or $\mathrm{HbA} 1 \mathrm{C} \geq 6.5 \%$.

Blood samples were collected after overnight fasting and stored at $-20^{\circ} \mathrm{C}$ until analysis. The concentrations of plasma glucose, serum albumin, blood urea nitrogen (BUN), creatinine, total cholesterol, and hemoglobin $(\mathrm{Hb})$ were measured using an automatic chemistry analyzer (Synchron LXi-725; Beckman Coulter Inc., Brea, CA, USA). The Kt/V value was calculated using Daugirdas' formula: - $\ln$ (Ratio-(0.03)) $+[(4-(3.5$ * Ratio $))$ * (Ultrafiltrate Volume/Weight $)]$, where ratio is the post-/pre-dialysis BUN ratio.

\section{Isolation of EPCs}

The blood sample was drawn at the time of patient enrollment and circulating EPCs were assayed within $1 \mathrm{~h}$ of blood withdrawal. Briefly, $10 \mathrm{~mL}$ venous blood was drawn from the antecubital vein and collected in a $4 \mathrm{~mL}$ tube containing heparin. Mononuclear cells (MNCs) were separated by Ficoll-Hypaque density gradient centrifugation (Ficoll-PlaqueTM plus, Amersham Biosciences, Sweden).After MNCs washing with phosphate buffer solution (PBS), cell 
were resuspended with $300 \mu \mathrm{L}$ PBS. Cell viability > 95.0\% was required in each group. EPC identity was determined by the co-expression of different stem cell markers (i.e., CD34, CD133) and endothelial cell (EC) lineage markers [i.e., kinase insert domain-conjugating receptor (KDR)]. Using immunofluorescent cell staining, the EPCs were identified by performing fluorescent conjugated monoclonal antibodies against fluorescein isothiocyanate (FITC)-conjugated CD34, APC-conjugated CD133, and phycoerythrin (PE)-conjugated KDR. The IgG2a-PE-FITC was used as a background control to eliminate any non-specific glycoprotein binding. Stain with PE-conjugated goat anti-mouse antibody was used to identify KDR positive MNCs. For fluorescence-activated cell-sorting analysis, quantitative three-color flow cytometric analysis was chosen (Beckman Coulter Cytomics FC500 Flow Cytometry). Calculation the number of EPC per 100,000 cells was performed and duplicate record reports the mean levels. To quantify the blood sample more precisely, intra-assay variability of the same sample was tested that mean coefficient of variation $<4.0 \%$ in necessary.

\section{Statistical analysis}

Continuous variables were represented as mean and standard deviation (SD) if normally distributed and compared by parametric test such as Student's t-test; variable that don't have normal distribution is compared with non-parametric test like Mann-Whitney U-test. The Kolmogorov-Smirnov test and Shapiro-Wilk test were commonly used to check if the variable has normal distribution. Chi-square test and Fisher's exact test were used to analyze categorical data.

The Kaplan-Meier estimation method was computed to assess the probability of survival and compared statistically using log rank test. Cox proportional hazard regression assumes the association between various clinical data and time of death. Confounding factors were included in multivariate models if they had significant associations in the univariate analysis or clinical evidence indicated a relationship with the risk of mortality. A two-tailed $\mathrm{p}$ value $<0.05$ was considered significant. All analyses were performed with IBM SPSS Statistics version 20.0 (SPSS Inc., Chicago, Ill., USA) and Stata/SE 10.0 (StataCorp LP, College Station TX) for Windows.

\section{Results}

The clinical characteristics of the participants are summarized in Table 1 based on the level of circulating EPCs. The number of circulating EPCs ranged from $2 / \mu \mathrm{L}$ to $10 / \mu \mathrm{L}$ (median $5.0 / \mu \mathrm{L}$ ), with a mean $( \pm \mathrm{SD})$ of $5.29 \pm 2.06 / \mu \mathrm{L}$. No significantly different variable factor was found between patients with high and low circulating EPC levels (Table 1). The cause of death was reviewed in $79(51.3 \%)$ hemodialysis patients during the follow-up period, 41 of whom died due to a confirmed cardiovascular cause. The cause of death is shown in detail in Table 2.

Table 1. Clinical characteristics and laboratory finding of study patients.

\begin{tabular}{|c|c|c|c|}
\hline Characteristics & $\begin{array}{l}\text { High-EPCs, EPC } \\
\geq 5 / \text { ul } \\
(n=56)\end{array}$ & $\begin{array}{l}\text { Low-EPCs, EPC } \\
<5 / \mathrm{ul} \\
(n=98)\end{array}$ & $p$ value \\
\hline Age (years) & $67.82 \pm 14.73$ & $70.29 \pm 15.98$ & $0.20 \dagger$ \\
\hline Male (\%) & $41(41.8 \%)$ & $31(55.4 \%)$ & $0.10 \#$ \\
\hline Body mass index $(\mathrm{kg} / \mathrm{m} 2)$ & $22.10 \pm 3.77$ & $22.08 \pm 3.90$ & $0.98 \dagger$ \\
\hline Hemodialysis duration (years) & $8.83 \pm 4.36$ & $8.38 \pm 4.28$ & $0.41 \dagger$ \\
\hline Current smoker & $17(17.3 \%)$ & $8(14.3 \%)$ & $0.62 \#$ \\
\hline Ever drinking & $3(3.1 \%)$ & $1(1.8 \%)$ & $1.00 !$ \\
\hline Diabetes mellitus & $58(59.2 \%)$ & $28(50.0 \%)$ & $0.27 \#$ \\
\hline Hypertension & $66(67.3 \%)$ & $40(71.4 \%)$ & $0.59 \#$ \\
\hline Pre-dialysis SBP (mmHg) & $143.73 \pm 24.59$ & $146.63 \pm 28.23$ & $0.52 \dagger$ \\
\hline $\begin{array}{l}\text { Endothelial progenitor cells } \\
(/ \mathrm{ul})\end{array}$ & $6.00 \pm 3.00$ & $3.00 \pm 1.00$ & $<0.01 \ddagger$ \\
\hline $\operatorname{Albumin}(\mathrm{g} / \mathrm{dL})$ & $3.65 \pm 0.56$ & $3.93 \pm 2.00$ & $0.55 \dagger$ \\
\hline Blood urea nitrogen $(\mathrm{mg} / \mathrm{dL})$ & $65.08 \pm 18.76$ & $66.93 \pm 14.11$ & $0.42 \dagger$ \\
\hline Creatinine(mg/dL) & $9.88 \pm 2.33$ & $9.71 \pm 2.55$ & $0.46 \dagger$ \\
\hline Calcium(mg/dL) & $9.00 \pm 0.79$ & $8.90 \pm 0.83$ & $0.73 \ddagger$ \\
\hline Phosphate(mg/dL) & $5.10 \pm 1.58$ & $4.90 \pm 1.55$ & $0.24 \ddagger$ \\
\hline $\begin{array}{l}\text { Intact parathyroid hormone } \\
(\mathrm{pg} / \mathrm{mL})\end{array}$ & $422.7 \pm 414.2$ & $440.6 \pm 434.7$ & $0.64 \ddagger$ \\
\hline Dialysis efficiency (Kt/Vurea) & $1.48 \pm 0.42$ & $1.49 \pm 0.33$ & $0.48 \dagger$ \\
\hline Total cholesterol $(\mathrm{mg} / \mathrm{dL})$ & $181.23 \pm 91.88$ & $159.21 \pm 39.19$ & $0.053 \dagger$ \\
\hline $\begin{array}{l}\text { Low-density lipopro- } \\
\text { tein(mg/dL) }\end{array}$ & $131.0 \pm 26.23$ & $132.0 \pm 16.89$ & $0.82 \ddagger$ \\
\hline $\begin{array}{l}\text { High-density lipopro- } \\
\text { tein }(\mathrm{mg} / \mathrm{dL})\end{array}$ & $29.0 \pm 6.3$ & $33.0 \pm 6.5$ & $0.24 \ddagger$ \\
\hline Blood glucose $(\mathrm{mg} / \mathrm{dL})$ & $130.51 \pm 65.76$ & $142.78 \pm 63.41$ & $0.18 \dagger$ \\
\hline Hemoglobin $(\mathrm{g} / \mathrm{dL})$ & $10.00 \pm 1.60$ & $9.55 \pm 1.60$ & $0.08 \ddagger$ \\
\hline
\end{tabular}

Table 2. Cause of death in hemodialysis patients.

\begin{tabular}{llll}
\hline Total & $\begin{array}{l}\text { High-EPCs group } \\
(\mathrm{n}=46)\end{array}$ & $\begin{array}{l}\text { Low-EPCs group P value } \\
(\mathrm{n}=33)\end{array}$ & \\
\hline Cardiovascular disease & $18(39.1 \%)$ & $23(69.7 \%)$ & $<0.01$ \\
Infectious disease & $11(23.9 \%)$ & $7(21.2 \%)$ & 0.78 \\
Malignant disease & $8(17.4 \%)$ & $1(3 \%)$ & 0.07 \\
Other disease & $9(20.0 \%)$ & $2(6 \%)$ & 0.11 \\
\hline
\end{tabular}

The Kaplan-Meier survival data for all patients were divided into two groups according to the median EPC level (Figure 1) at the time of enrollment: high-EPC group (EPCs $\geq 5$ cells $/ \mu \mathrm{L}$ ) or low-EPC group (EPCs $<5$ cells $/ \mu \mathrm{L}$ ). The cumulative survival was greater in the high-EPC group than the low-EPC group for all-cause mortality $(p=0.034$, log-rank test; Figure 1A) and cardiovascular mortality $(p=0.035$, log-rank test; Figure 1B). For all-cause mortality, the $1-, 3-$, and 5-year cumulative survival rates for the 
high-EPC group were $98.0 \%, 73.5 \%$, and $46.9 \%$, and in the low-EPC group $94.6 \%, 55.4 \%$, and $35.7 \%$, respectively. The Receiver-operating characteristic curve analysis identify the significant predictive power of EPC level in all-cause mortality (area under the curve $=0.75, \mathrm{p}<0.01)$ (Figure 2).

The association between the level of circulating EPCs and patient survival according to the univariate Cox regression model is presented in Figure 3 and Figure 4. In a model using the forced-entry method, decreased EPC levels were associated with a significant increase in the risk of all-cause mortality (HR $0.750, p<0.01$; Figure 3). The incidence of all-cause death was also significantly influenced by age (HR

A

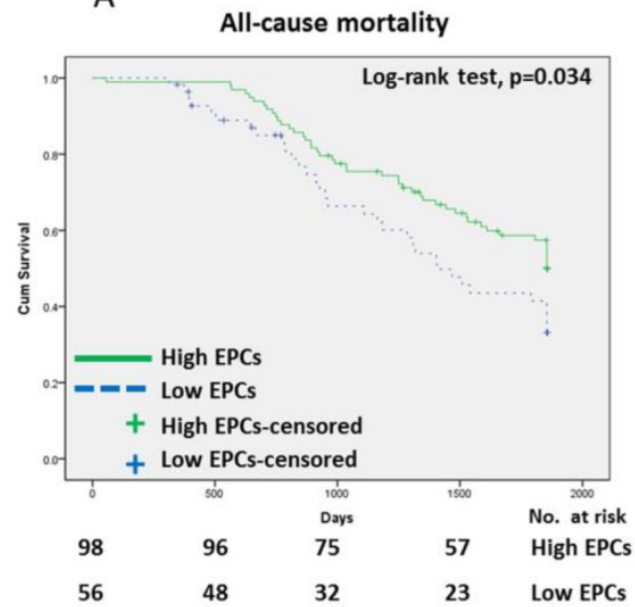

1.031 [95\% CI, 1.014-1.049], $p<0.01$; Figure 3). In addition, the variable serum creatinine and $\mathrm{Hb}$ levels were also significant prognostic factors associated with survival in all hemodialysis patients (serum creatinine: HR 0.898 [95\% CI, 0.811-0.994], $p=0.04 ; \mathrm{Hb}$ : HR 0.858 [95\% CI, 0.710-0.995], $p=0.04$; Figure 3).After adjusting for age, gender, current smokers, diabetes mellitus, and hypertension, the association between decreased EPC levels and increased risk of all-cause death remained significant (HR $0.737 \quad[95 \% \quad \mathrm{CI}$, 0.653-0.832], $p<0.01$; Table 3, Model 2, All-cause mortality). In other words, every $1 / \mathrm{uL}$ increase of EPC might reduce $26 \%$ risk of all-cause mortality.

B

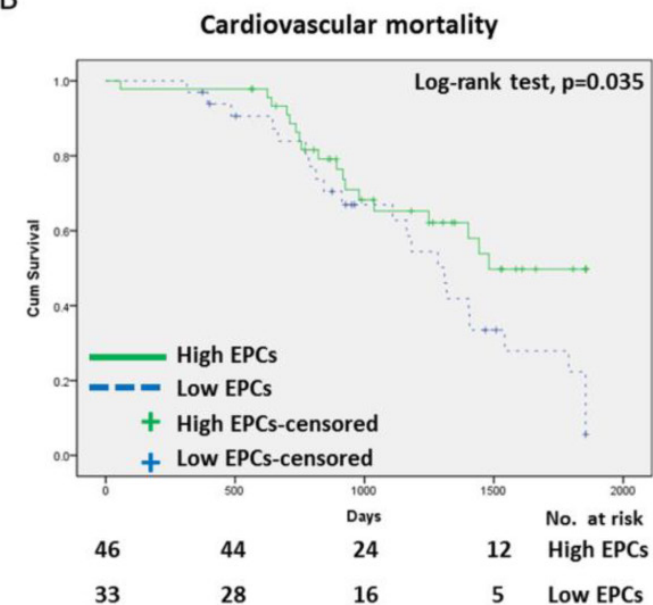

Figure 1. Cumulative survival curves for hemodiallysis patients. (A) All-cause mortality, (B) Cardiovascular mortality.

Table 3. Hazard ratio $(95 \% \mathrm{Cl})$ of risk factors in all hemodialysis patients, as determined by multivariate Cox's proportional regression hazard models.

\begin{tabular}{|c|c|c|c|c|c|c|}
\hline & \multicolumn{3}{|c|}{ All-cause mortality } & \multicolumn{3}{|c|}{ Cardiovascular mortality } \\
\hline & Model 1 & Model 2 & Model 3 & Model 1 & Model 2 & Model 3 \\
\hline $\begin{array}{l}\text { Harrell's } \\
\text { Concordance }\end{array}$ & 0.7193 & 0.7232 & 0.7258 & 0.7275 & 0.7433 & 0.7492 \\
\hline Endothelial progenitor cells & $\begin{array}{l}0.742^{*} \\
(0.658-0.837)\end{array}$ & $\begin{array}{l}0.737^{*} \\
(0.653-0.832)\end{array}$ & $\begin{array}{l}0.745^{*} \\
(0.658-0.844)\end{array}$ & $\begin{array}{l}0.790^{*} \\
(0.651-0.959)\end{array}$ & $\begin{array}{l}0.783^{*} \\
(0.641-0.955)\end{array}$ & $\begin{array}{l}0.787^{*} \\
(0.645-0.959)\end{array}$ \\
\hline Age & $\begin{array}{l}1.032^{*} \\
(1.014-1.049)\end{array}$ & $\begin{array}{l}1.034^{*} \\
(1.016-1.052)\end{array}$ & $\begin{array}{l}1.038^{*} \\
(1.019-1.057)\end{array}$ & $\begin{array}{l}1.022 \\
(0.998-1.046)\end{array}$ & $\begin{array}{l}1.020 \\
(0.995-1.046)\end{array}$ & $\begin{array}{l}1.019 \\
(0.994-1.046)\end{array}$ \\
\hline Male & $\begin{array}{l}0.846 \\
(0.539-1.327)\end{array}$ & $\begin{array}{l}0.911 \\
(0.560-1.484)\end{array}$ & $\begin{array}{l}1.029 \\
(0.609-1.739)\end{array}$ & $\begin{array}{l}1.234 \\
(0.623-2.444)\end{array}$ & $\begin{array}{l}1.323 \\
(0.651-2.687)\end{array}$ & $\begin{array}{l}1.278 \\
(0.614-2.661)\end{array}$ \\
\hline Current smoker & & $\begin{array}{l}1.477 \\
(0.795-2.746)\end{array}$ & $\begin{array}{l}1.459 \\
(0.780-2.729)\end{array}$ & & $\begin{array}{l}1.591 \\
(0.705-3.589)\end{array}$ & $\begin{array}{l}1.648 \\
(0.725-3.750)\end{array}$ \\
\hline Diabtes mellitus & & $\begin{array}{l}1.119 \\
(0.709-1.766)\end{array}$ & $\begin{array}{l}1.459 \\
(0.780-2.729)\end{array}$ & & $\begin{array}{l}1.490 \\
(0.771-2.880)\end{array}$ & $\begin{array}{l}1.472 \\
(0.754-2.876)\end{array}$ \\
\hline Hypertension & & $\begin{array}{l}0.861 \\
(0.514-1.444)\end{array}$ & $\begin{array}{l}0.821 \\
(0.485-1.390)\end{array}$ & & $\begin{array}{l}0.625 \\
(0.298-1.309)\end{array}$ & $\begin{array}{l}0.609 \\
(0.287-1.290)\end{array}$ \\
\hline Dialysis efficiency (Kt/V) & & & $\begin{array}{l}0.422^{*} \\
(0.190-0.937)\end{array}$ & & & $\begin{array}{l}1.039 \\
(0.291-3.708)\end{array}$ \\
\hline Hemoglobulin & & & $\begin{array}{l}0.909 \\
(0.770-1.073)\end{array}$ & & & $\begin{array}{l}0.935 \\
(0.736-1.187)\end{array}$ \\
\hline
\end{tabular}

${ }^{*} \mathrm{p}<0.05$ 
The higher circulating level of EPCs had significantly positive benefits of reducing death from cardiovascular cause (HR 0.816 [95\% CI, 0.674-0.988], $p=0$. 04; Figure 4). Multivariate analysis adjusted for age, gender, current smokers, diabetes mellitus, and hypertension confirmed an independent significant association between EPC level and cardiovascular mortality (HR 0.783 [95\% CI, 0.641-0.955], $p=0.015$; Table 3, Model 2, Cardiovascular mortality). In addition, EPC level was also independently predicted cardiovascular mortality after adjusting for known important confounding factors in hemodialysis patients, such as HDL-C, LDL-C, calcium, phosphate, intact parathyroid hormone and history of cardiovascular disease (HR 0.712 [95\% CI, 0.572-0.888], $p$ $<0.01)$. Using univariate logistic regression, no variable other than circulating EPCs had enough significance to predict cardiovascular mortality in our study.

The Harrell's C indexes of concordance statistics indicated good predictability in each model (0.7193-0.7492; Table 3). The increments in concordance statistics for EPCs in Model 1 were 0.0037 and 0.0083 for all-cause mortality and cardiovascular mortality, respectively. Age and level of circulating EPCs increased the concordance statistics in all models.

\section{Discussion}

To the best of our knowledge, this is the first study to demonstrate that the number of circulating EPCs predicts all-cause and cardiovascular mortality in patients undergoing hemodialysis for at least 3 months. This study had a longer follow-up period, which allowed us to clarify the association between circulating EPC levels and clinical outcome.

In the last decade, EPCs have been the focus of investigation for vascular injury, cardiovascular events, and response to therapy. The level of circu- lating EPCs has been inversely correlated with atherosclerotic risk factors in coronary artery disease (4) and advanced heart failure (5). The level of EPCs has also been shown to be a surrogate biological marker of vascular function (6) or cumulative cardiovascular risk in the general population $(7,8)$. Statins can induce the proliferative capacity of EPCs in vitro by preventing senescence (9). The angiotensin-converting enzyme inhibitor, ramipril, can enhance the functional activity of EPCs in patients with coronary artery disease (10), and rosiglitazone can increase the level and improve the migratory function of circulating EPCs in type 2 diabetic patients via up-regulation of the Akt/eNOS pathways $(11,12)$. These phenomena indicate the therapeutic potential of EPC transplantation in patients with cardiovascular diseases.

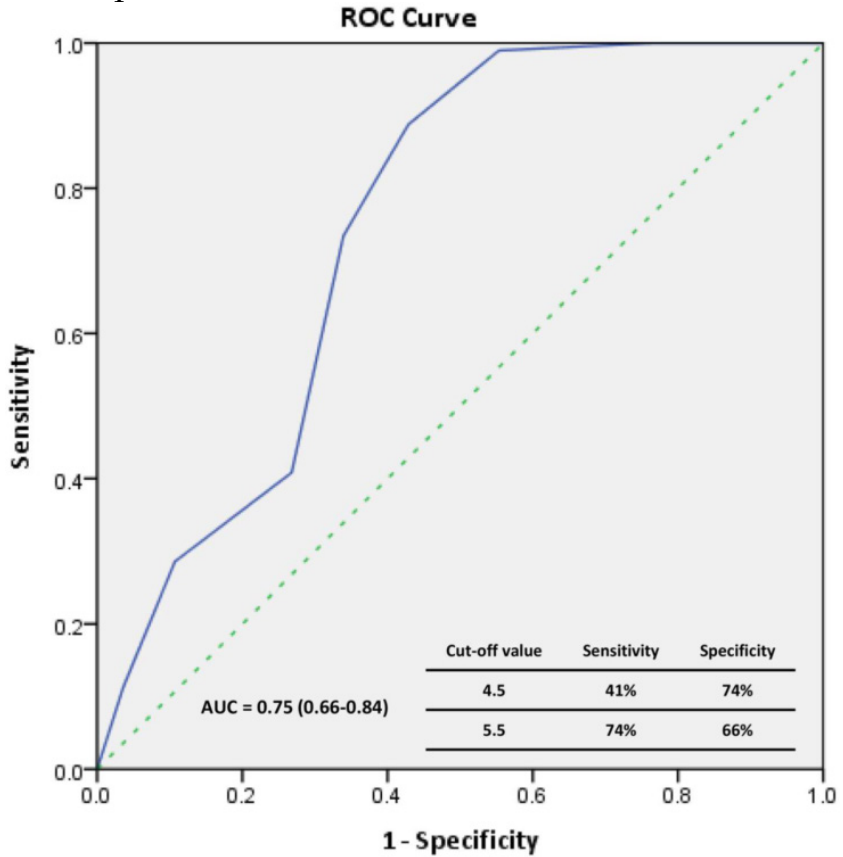

Figure 2. The receiver operating characteristic (ROC) curve for the EPCs to predict patient's all-cause mortality.

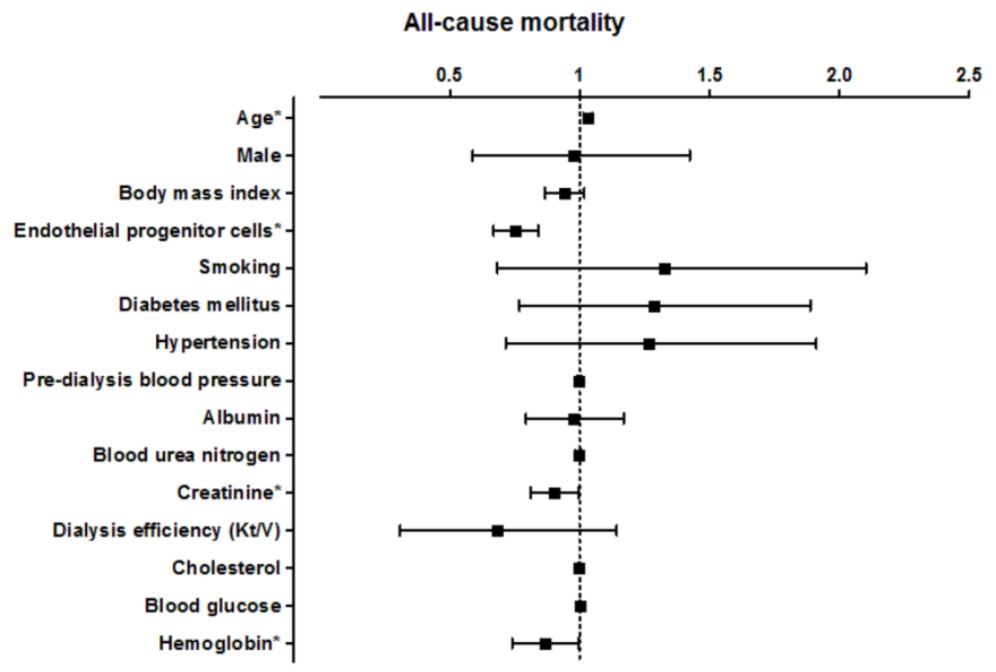

Figure 3. Hazard ratio for various factors for all-cause mortality in all hemodialysis patients. 


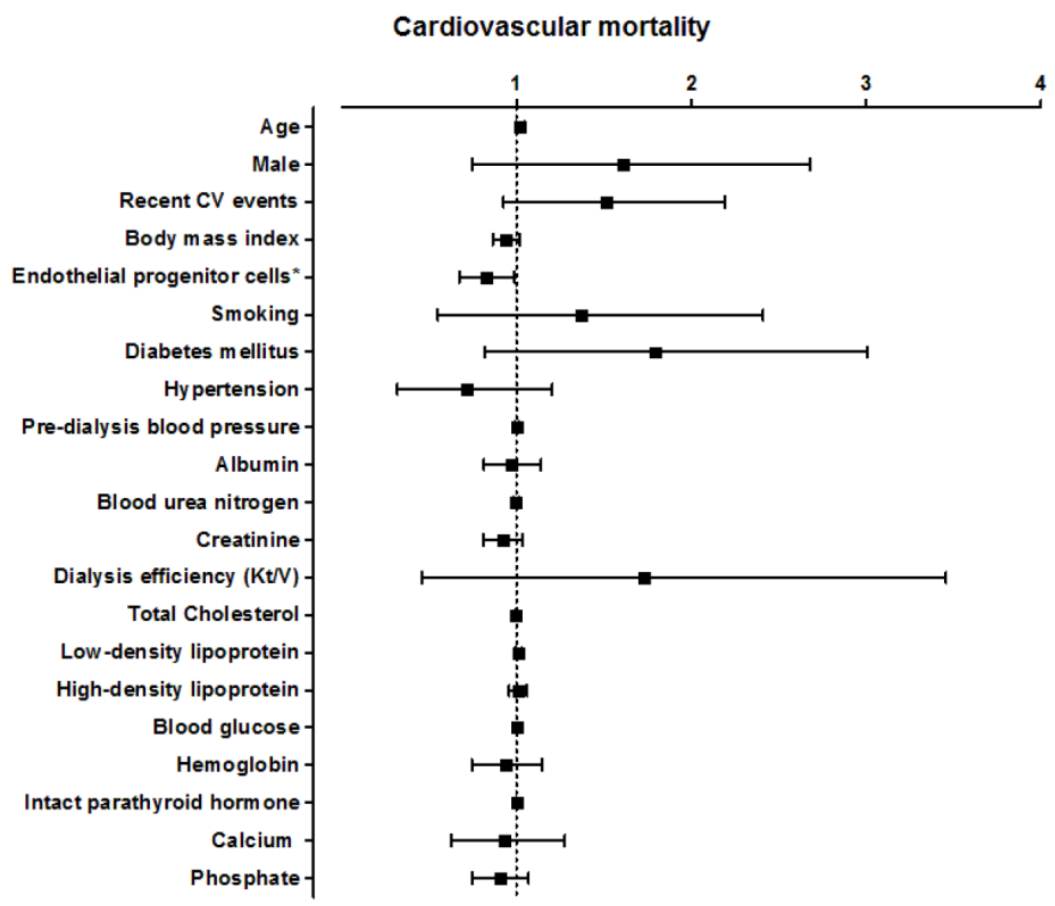

Figure 4. Hazard ratio for various factors for cardiovascular mortality in all hemodialysis patients.

In CKD, the circulating number $(13,14)$, colony formation, migratory ability, adhesion (15), and angiogenic function(16) of EPCs are decreased $(16,17)$; thus, EPC dysfunction is a critical event in the initiation of atherosclerotic plaque development and the level of circulating EPCs can be considered a biomarker of cardiovascular events in patient on maintenance hemodialysis $(18,19)$. The uremic toxin can inhibit EPC activity and differentiation in vitro; therefore, imitating the dialysis modality may ameliorate the EPC level and restore angiogenesis (20). Compared to conventional hemodialysis, nocturnal hemodialysis is associated with significant improvement in the ability of EPCs to promote tissue perfusion in ischemic insult (21).

The aim of our study was to investigate the level of circulating $\mathrm{CD} 34^{+} / \mathrm{CD} 133^{+} / \mathrm{KDR}^{+}$EPCs based on all-cause and cardiovascular mortality in patients on maintenance hemodialysis. No variable significantly differed between the high-EPC and low-EPC group. Notably, the cumulative survival curve in the low-EPC group $(\mathrm{EPC}<5 / \mu \mathrm{L})$ predicted poor survival for all-cause mortality and cardiovascular mortality. Lee et al. concluded that a decreased level of circulating EPCs is associated with cardiovascular events but not all-cause mortality(18). The proportion of deaths from all-cause mortality in this study was $51.3 \%(79 / 154)$, whereas Lee et al. reported that $7 \%$ $(5 / 70)$ of hemodialysis patients in their study died, all from cardiovascular causes. With a large sample size and longer follow-up, this study confirmed the significance association between the level of circulating
EPCs and patient survival. Moreover, Maruyama et al. demonstrated that circulating $\mathrm{CD} 4^{+}$hematopoietic stem cells are significantly associated with vascular risk and all-cause mortality in chronic hemodialysis patients (22). However, screening for CD34/CD133/KDR triple-positive cells rather than only CD34-positive cells can more accurately characterize EPCs, as some circulating mature endothelial cells also express CD34, stem cell marker CD133 acts as a more suitable marker of EPCs (23), and CD133/KDR dual-positive cells exhibit a greater capacity to migrate and differentiate into mature endothelial cells in postnatal vasculogenesis.

In univariate analysis, the level of circulating EPCs was significantly associated with all-cause and cardiovascular mortality. Even after adjusting for covariates, a low level of circulating EPCs was an independent predictor of poor prognosis. Limited studies have shown that the level of circulating EPCs has an influence on prognosis. Among patients with acute lung injury, decreased levels of circulating EPC colonies were associated with an increased risk of death after multivariate adjustment (24). Among patients with coronary artery disease confirmed on angiography, decreased levels of circulating EPCs were associated with an increased risk of death from cardiovascular disease, but not death from all-cause mortality after multivariate adjustment (25). Among CKD and hemodialysis patients, the EPC level has been shown to be an independent predictor of cardiovascular events $(18,19)$. In the present study, we further clarified the role of the level of circulating 
EPCs in predicting all-cause and cardiovascular mortality in patients on maintenance hemodialysis.

Vitamin D has the positive effect on the number of circulating EPC and optimal level of 25-vitamind D can reduce the risk of cardiovascular event and diabetes(26). Calcitriol, active form vitamin $\mathrm{D}_{3}$, stimulate endothelial colony-forming cells (ECFCs) proliferation through increasing VEGF expression and pro-MMP-2 activity in vitro, which is very important in angiogenesis(27). Deficiency of vitamin D might decrease the EPC number and function in hemodialysis patients (28). HMG-CoA reductase inhibitors (statins) increase the number of EPC by inducing bone marrow hematopoietic precursor cell differentiation through PI3K/Akt pathway (29) and to improve the vascular wall pathology in balloon induced injury (30). This offers another explanation of clinical benefit of statin therapy in coronary artery disease patient (31). Erythropoietin had been reported to improve cardiac function after myocardial infarction by the proangiogenic properties of EPC $(32,33)$. Administration of erythropoietin can increase the number of functionally active EPC by Akt protein kinase pathway and then repair the vascular injury caused by ischemia or inflammation $(34,35)$. Also, angiotensin II-related blocker affects the number of EPC (36). In vitro study, uremic toxins such as $\beta 2$-microglobulin and indole-3 acetic acid may also induce EPC apoptosis during early differentiation (37). Taken together, numerous factors had been shown to be associated with the number of EPC in hemodialysis patients and each of those possibly influence the role of EPC level as a prognostic marker.

Our study has several limitations. First, we did not take into account EPC colonies to determine the functional change in hemodialysis patients. Second, a limited number of confounding factors were recorded and adjusted for in the Cox regression model. To confirm the utility of EPC levels in predicting mortality, a multicenter interventional study with a larger number of patients and multiple dialysis centers is needed.

\section{Conclusion}

The level of circulating EPCs in hemodialysis patients is worthy of consideration, as low EPC levels were associated with death from all-cause and cardiovascular mortality. These findings suggest that circulating EPC levels independently predict the clinical outcome in patients on maintenance hemodialysis. Thus, the EPCs levels may be a useful predictive tool for evaluating the risk of death in maintenance hemodialysis patients.

\section{Abbreviations}

EPC: endothelial progenitor cells; KDR: Kinase insert domain-conjugating receptor; MNCs: mononuclear cells; VEGF: vascular endothelial growth factor; CKD: chronic kidney disease; SBP: systolic blood pressure; BUN: Blood urea nitrogen; Kt/Vurea: Dialysis efficiency; Hb: Hemoglobulin.

\section{Acknowledgments}

This work is supported by a grant from the Cardinal Tien Hospital (CTH-NC-100-03) and Tri-Service General Hospital (TSGH-C105-006-008-S03).

\section{Competing Interests}

The authors have declared that no competing interest exists.

\section{References}

1. Tilling L, Chowienczyk P, Clapp B. Progenitors in motion: mechanisms of mobilization of endothelial progenitor cells. British journal of clinical pharmacology. 2009; 68: 484-92

2. Stam F, van Guldener C, Becker A, et al. Endothelial dysfunction contributes to renal function-associated cardiovascular mortality in a population with mild renal insufficiency: the Hoorn study. Journal of the American Society of Nephrology : JASN. 2006; 17: 537-45.

3. Futrakul N, Butthep P, Futrakul P. Altered vascular homeostasis in chronic kidney disease. Clinical hemorheology and microcirculation. 2008; 38: 201-7.

4. Vasa M, Fichtlscherer S, Aicher A, et al. Number and migratory activity of circulating endothelial progenitor cells inversely correlate with risk factors for coronary artery disease. Circ Res. 2001; 89: E1-7.

5. Valgimigli M, Rigolin GM, Fucili A, et al. CD34+ and endothelial progenitor cells in patients with various degrees of congestive heart failure. Circulation. 2004; 110: 1209-12.

6. Glowinska-Olszewska B, Luczynski W, Bossowski A. [Endothelial progenitor cells as a new marker of endothelial function with respect to risk of cardiovascular disorders]. Postepy higieny i medycyny doswiadczalnej. 2011; 65: 8-15.

7. Hill JM, Zalos G, Halcox JP, et al. Circulating endothelial progenitor cells, vascular function, and cardiovascular risk. The New England journal of medicine. 2003; 348: 593-600.

8. Shantsila E, Watson T, Lip GY. Endothelial progenitor cells in cardiovascular disorders. Journal of the American College of Cardiology. 2007; 49: 741-52.

9. Assmus B, Urbich C, Aicher A, et al. HMG-CoA reductase inhibitors reduce senescence and increase proliferation of endothelial progenitor cells via regulation of cell cycle regulatory genes. Circ Res. 2003; 92: 1049-55.

10. Min TQ, Zhu CJ, Xiang WX, et al. Improvement in endothelial progenitor cells from peripheral blood by ramipril therapy in patients with stable coronary artery disease. Cardiovasc Drugs Ther. 2004; 18: 203-9.

11. Pistrosch F, Herbrig K, Oelschlaegel U, et al. PPARgamma-agonist rosiglitazone increases number and migratory activity of cultured endothelial progenitor cells. Atherosclerosis. 2005; 183: 163-7.

12. Liang C, Ren $\mathrm{Y}$, Tan $\mathrm{H}$, et al. Rosiglitazone via upregulation of Akt/eNOS pathways attenuates dysfunction of endothelial progenitor cells, induced by advanced glycation end products. British journal of pharmacology. 2009; 158: 1865-73.

13. Eizawa T, Murakami Y, Matsui K, et al. Circulating endothelial progenitor cells are reduced in hemodialysis patients. Current medical research and opinion. 2003; 19: 627-33.

14. Chen YT, Cheng BC, Ko SF, et al. Value and level of circulating endothelial progenitor cells, angiogenesis factors and mononuclear cell apoptosis in patients with chronic kidney disease. Clinical and experimental nephrology. 2013; 17: 83-91.

15. Herbrig K, Pistrosch F, Oelschlaegel U, et al. Increased total number but impaired migratory activity and adhesion of endothelial progenitor cells in patients on long-term hemodialysis. American journal of kidney diseases : the official journal of the National Kidney Foundation. 2004; 44: 840-9.

16. Choi JH, Kim KL, Huh W, et al. Decreased number and impaired angiogenic function of endothelial progenitor cells in patients with chronic renal failure. Arteriosclerosis, thrombosis, and vascular biology. 2004; 24: 1246-52.

17. Rodriguez-Ayala E, Yao Q, Holmen C, et al. Imbalance between detached circulating endothelial cells and endothelial progenitor cells in chronic kidney disease. Blood purification. 2006; 24: 196-202

18. Lee HJ, Kim W, Kim WS, et al. Circulating Endothelial Progenitor Cell Levels Predict Cardiovascular Events in End-Stage Renal Disease Patients on Maintenance Hemodialysis. Nephron. 2015; 130: 151-8.

19. Lorenzen J, David S, Bahlmann FH, et al. Endothelial progenitor cells and cardiovascular events in patients with chronic kidney disease--a prospective follow-up study. PloS one. 2010; 5: e11477. 
20. de Groot K, Bahlmann FH, Sowa J, et al. Uremia causes endothelial progenitor cell deficiency. Kidney international. 2004; 66: 641-6.

21. Yuen DA, Kuliszewski MA, Liao C, et al. Nocturnal hemodialysis is associated with restoration of early-outgrowth endothelial progenitor-like cell function. Clinical journal of the American Society of Nephrology : CJASN. 2011; 6: 1345-53.

22. Maruyama S, Taguchi A, Iwashima S, et al. Low circulating CD34+ cell count is associated with poor prognosis in chronic hemodialysis patients. Kidney international. 2008; 74: 1603-9.

23. Khakoo AY, Finkel T. Endothelial progenitor cells. Annu Rev Med. 2005; 56: 79-101.

24. Burnham EL, Taylor WR, Quyyumi AA, et al. Increased circulating endothelial progenitor cells are associated with survival in acute lung injury. Am J Respir Crit Care Med. 2005; 172: 854-60.

25. Werner N, Kosiol S, Schiegl T, et al. Circulating endothelial progenitor cells and cardiovascular outcomes. The New England journal of medicine. 2005; 353: 999-1007.

26. Mikirova NA, Belcaro G, Jackson JA, et al. Vitamin D concentrations, endothelial progenitor cells, and cardiovascular risk factors. Panminerva medica. 2010; 52: 81-7.

27. Grundmann M, Haidar M, Placzko S, et al. Vitamin D improves the angiogenic properties of endothelial progenitor cells. American journal of physiology Cell physiology. 2012; 303: C954-62.

28. Cianciolo G, La Manna G, Cappuccilli ML, et al. VDR expression on circulating endothelial progenitor cells in dialysis patients is modulated by $25(\mathrm{OH}) \mathrm{D}$ serum levels and calcitriol therapy. Blood purification. 2011; 32: 161-73.

29. Dimmeler S, Aicher A, Vasa M, et al. HMG-CoA reductase inhibitors (statins) increase endothelial progenitor cells via the PI 3-kinase/Akt pathway. The Journal of clinical investigation. 2001; 108: 391-7.

30. Walter DH, Rittig K, Bahlmann FH, et al. Statin therapy accelerates reendothelialization: a novel effect involving mobilization and incorporation of bone marrow-derived endothelial progenitor cells. Circulation. 2002; 105: 3017-24.

31. Vasa M, Fichtlscherer S, Adler K, et al. Increase in circulating endothelial progenitor cells by statin therapy in patients with stable coronary artery disease. Circulation. 2001; 103: 2885-90.

32. Westenbrink BD, Lipsic E, van der Meer P, et al. Erythropoietin improves cardiac function through endothelial progenitor cell and vascular endothelial growth factor mediated neovascularization. European heart journal. 2007; 28: 2018-27.

33. van der Meer P, Lipsic E, Henning RH, et al. Erythropoietin induces neovascularization and improves cardiac function in rats with heart failure after myocardial infarction. Journal of the American College of Cardiology. 2005; 46: $125-33$.

34. Satoh K, Kagaya Y, Nakano M, et al. Important role of endogenous erythropoietin system in recruitment of endothelial progenitor cells in hypoxia-induced pulmonary hypertension in mice. Circulation. 2006; 113: 1442-50.

35. Heeschen C, Aicher A, Lehmann R, et al. Erythropoietin is a potent physiologic stimulus for endothelial progenitor cell mobilization. Blood. 2003; 102: 1340-6.

36. Bahlmann FH, de Groot K, Mueller O, et al. Stimulation of endothelial progenitor cells: a new putative therapeutic effect of angiotensin II receptor antagonists. Hypertension. 2005; 45: 526-9.

37. Jourde-Chiche N, Dou L, Sabatier F, et al. Levels of circulating endothelial progenitor cells are related to uremic toxins and vascular injury in hemodialysis patients. Journal of thrombosis and haemostasis : JTH. 2009; 7: 1576-84 